University of Louisville

ThinkIR: The University of Louisville's Institutional Repository

Faculty Scholarship

2015

\title{
Aerobic and resistance training improves mood state among adults living with HIV.
}

\author{
Jason R. Jaggers \\ University of Louisville, jason.jaggers@louisville.edu \\ Gregory A. Hand \\ West Virginia University \\ Wesley D. Dudgeon \\ College of Charleston \\ Stephanie Burgess \\ University of South Carolina - Columbia \\ Kenneth D. Phillips \\ University of Tennessee, Knoxville \\ See next page for additional authors \\ Follow this and additional works at: https://ir.library.louisville.edu/faculty \\ Part of the Exercise Science Commons, and the Sports Sciences Commons
}

\section{Original Publication Information}

Jaggers, J. R., et al. "Aerobic and Resistance Training Improves Mood State among Adults Living with HIV." 2015. International Journal of Sports Medicine 36(2): 175-181.

\section{ThinkIR Citation}

Jaggers, Jason R.; Hand, Gregory A.; Dudgeon, Wesley D.; Burgess, Stephanie; Phillips, Kenneth D.;

Durstine, Larry; and Blair, Steven N., "Aerobic and resistance training improves mood state among adults living with HIV." (2015). Faculty Scholarship. 415.

https://ir.library.louisville.edu/faculty/415

This Article is brought to you for free and open access by ThinkIR: The University of Louisville's Institutional Repository. It has been accepted for inclusion in Faculty Scholarship by an authorized administrator of ThinkIR: The University of Louisville's Institutional Repository. For more information, please contact thinkir@louisville.edu. 


\section{Authors}

Jason R. Jaggers, Gregory A. Hand, Wesley D. Dudgeon, Stephanie Burgess, Kenneth D. Phillips, Larry Durstine, and Steven N. Blair 


\section{Aerobic and Resistance Training Improves Mood State among Adults Living with HIV}

Authors

Affiliations

\author{
J. R. Jaggers' ${ }^{1}$, G. A. Hand ${ }^{2}$, W. D. Dudgeon ${ }^{3}$, S. Burgess ${ }^{4}$, K. D. Phillips ${ }^{5}$, J. L. Durstine² , S. N. Blair ${ }^{2}$
}

Affiliation addresses are listed at the end of the article

Key words
clinical trial
stress
depression
exercise
physical activity

accepted after revision June 12, 2014

Bibliography

DOI http://dx.doi.org/

$10.1055 / \mathrm{s}-0034-1385878$

Published online:

October 16, 2014

Int J Sports Med 2015; 36:

175-181 @ Georg Thieme

Verlag KG Stuttgart · New York ISSN 0172-4622

\section{Correspondence}

\section{Dr. Jason R. Jaggers}

Applied Health Sciences Murray State University 403 Applied Health Building North

Murray

United States 42071

Tel.: + 1/270/809 6285

Fax: + 1/270/809 3815

jjaggers2@murraystate.edu

\section{Abstract}

$\nabla$

The purpose of this investigation was to examine the effects of combined aerobic and resistance exercise training among self-reported mood disturbances, perceived stress, frequency of selfreported symptoms, and symptom distress in a sample of HIV + adults. For this purpose, 49 participants were randomly assigned into an exercise (EX) or control (CON) group. Those in the EX group completed 50 min of supervised aerobic and resistance training at a moderate intensity twice a week for 6 weeks. The CON group reported to the university and engaged in sedentary activities. Data were collected at baseline before randomization and 6 weeks post interven-

\section{Introduction}

$\nabla$

Living with HIV introduces multiple physical and psychological challenges to those with a positive serostatus. A few of the burdens people living with HIV/AIDS (PLWHA) face after diagnosis include the adjustment to daily struggles with managing the illness and the instant feeling of stigmatization. Additional environmental factors could potentially exacerbate stress levels further considering the emerging patient demographics. For example, studies have shown a positive association among stress and environment that incorporated poverty, lower level of education, reduced access to health care, and an increased likelihood of past or current drug use $[20,31,39]$. The majority of new HIV cases reported every year over the last decade have been among minorities from lower socioeconomic demographics [4]. With strong findings indicating a detrimental effect of chronic stress on health it seems warranted that in a population with an already lowered immune system, such as HIV patients, a safe and effective treatment intervention needs to be implemented to help PLWHA tion. Measures included the symptom distress scale (SDS), perceived stress scale (PSS), profile of mood states (POMS) total score, and the POMS sub-scale for depression and fatigue. A 2 way ANOVA was used to compare between and within group interactions. The EX group showed a significant decrease in reported depression scores $(p=0.03)$ and total POMS $(p=0.003)$. The CON group reported no change in POMS or SDS, but showed a significant increase in PSS. These findings indicate that combination aerobic and resistance training completed at a moderate intensity at least twice a week provides additional psychological benefits independent of disease status and related symptoms.

self-manage the physical and psychological consequences of chronic stress.

Chronic stress is known to increase the risk of illness in healthy populations as well as the rate of disease progression among clinical populations $[20,25,26,40,43]$. It was recently shown among elderly caregivers that psychological distress (perceived stress) is associated with negative immune system changes such as a decreased percentage of T-helper cells [12,34]. Other studies observing various clinical populations have investigated the consequences of psychological distress among patients. Reported findings have continuously shown perceived stress to have significant associations with mood disturbances [44], poor treatment adherence [8], and negative health outcomes [5]. Similar results are being observed among HIV-infected persons [3,5, 14,30,31,35]. Studies have shown that due to chronic stress PLWHA often have significantly higher amounts of circulating cortisol, which can lead to additional health consequences $[3,10,11]$. Furthermore, PLWHA will often experience some level of distress associated with HIV-related symptoms. 
Individuals with HIV often experience both disease and treatment-related symptoms, with literature reporting prevalence rates of over $50 \%$. It is often rare that a single symptom is reported, as current data suggests that PLWHA experience multiple symptoms concurrently $[16,23,36]$. Some of the most common physical symptoms reported include diarrhea, loss of appetite, nausea, muscle weakness, peripheral neuropathy, fever, dry skin, and persistent cough. In addition a variety of common psychological symptoms such as disorientation, trouble concentrating, depression, fatigue and anxiety have also been reported. The management of multiple symptoms has become a daily task for PLWHA in an effort to maintain an optimal quality of life $[35,36]$.

A major contributor to physical inactivity, fatigue is one of the most common symptoms reported among PLWHA, involving both physical and psychological detriments [18,41]. Consequently it is common for this population to report lower levels of physical activity [2], leading to a reduced functional capacity and health-related quality of life $[15,33]$. Numerous investigations have shown significant benefits of aerobic exercise in HIVinfected persons in areas of cardiorespiratory capacity, immune status, and metabolic activity, as well as psychological effects such as a reduction in symptoms of depression and anxiety $[15,24,42]$.

Some of the original clinical exercise trials studying HIV populations compared the effects of aerobic exercise on psychological distress components, such as depression and anxiety. 8 weeks of moderate-intensity aerobic exercise completed twice a week for $60 \mathrm{~min}$ has shown significant reductions in anxiety and depression [13]. Similar studies with HIV + men who exercised for $45 \mathrm{~min}$ a day, 3 days a week showed these men to have reduced anxiety and depression upon learning of their seropositive status $[21,22]$. Limitations to these early investigations are evident because they were conducted prior to antiretroviral therapy (ART), when symptoms were specific to viral progression and not treatment. Furthermore, the majority of were middle class gay men. Due to the shift in patient demographics and available treatments, those findings lack generalizability for today's seropositive populations.

It is well known that regular exercise improves psychological health and can reduce circulating cortisol, a physiological indicator of stress, in the general population. However, the research among HIV-infected persons is scarce. With an already lowered immune function, the harmful side effects of stress on immunity may leave PLWHA vulnerable to physical/mental illness and disease progression. It is unknown whether or not the virus, or any antiretroviral, would inhibit specific exercise-induced adaptations observed among other clinical and healthy populations. The purpose of this investigation was therefore to determine the effects of a 6-week moderate intensity exercise intervention on self-reported mood-disturbances, frequency of self-reported symptoms, mood state and psychological distress among PLWHA.

\section{Methods}

$\nabla$

\section{Sample and setting}

A total of $116 \mathrm{HIV}+$ males and females were recruited for this randomized exercise trial and assessed for eligibility. Recruitment of participants was performed at local AIDS service organizations and health clinics following IRB approval. The inclusion criteria were receiving a positive HIV diagnosis, being 18 years of age or older, having no known opportunistic infections and being physically able to complete the exercise intervention. No person was excluded based on gender or ethnicity. This study meets the ethical standards of the International Journal of Sports Medicine [17].

Individuals were excluded from the study if: (1) their medical history revealed current opportunistic infection(s); (2) they were currently using hormone therapy or had received it in the past; (3) they scored 5 or greater on the Drug Abuse Screening Test (DAST) and/or the Michigan Alcohol Screening Test (MAST); (4) they reported current involvement in a structured exercise program; or (5) any contraindications for testing, as specified by the American College of Sports Medicine, were identified.

Of the 116 participants screened, 23 were ineligible, 44 were lost to follow-up or withdrew from the study, and 49 completed the protocol ( $\bullet$ Fig. 1). Although 49 subjects successfully completed the 6 -week intervention, 3 were missing total SDS scores and 2 had incomplete POMS data. Therefore only 44 were used for data analysis.

\section{Procedure}

Individuals who successfully met the inclusion/exclusion criteria were contacted for further screening. After providing consent, participants completed a medical history questionnaire and were interviewed by a research staff member. All data collection and testing procedures were completed at the Clinical Exercise Research Center (CERC) on campus at a university in the southeastern United States. Those who consented to participate were assigned a personal identification number and agreed complete a pre-intervention study packet which included col-

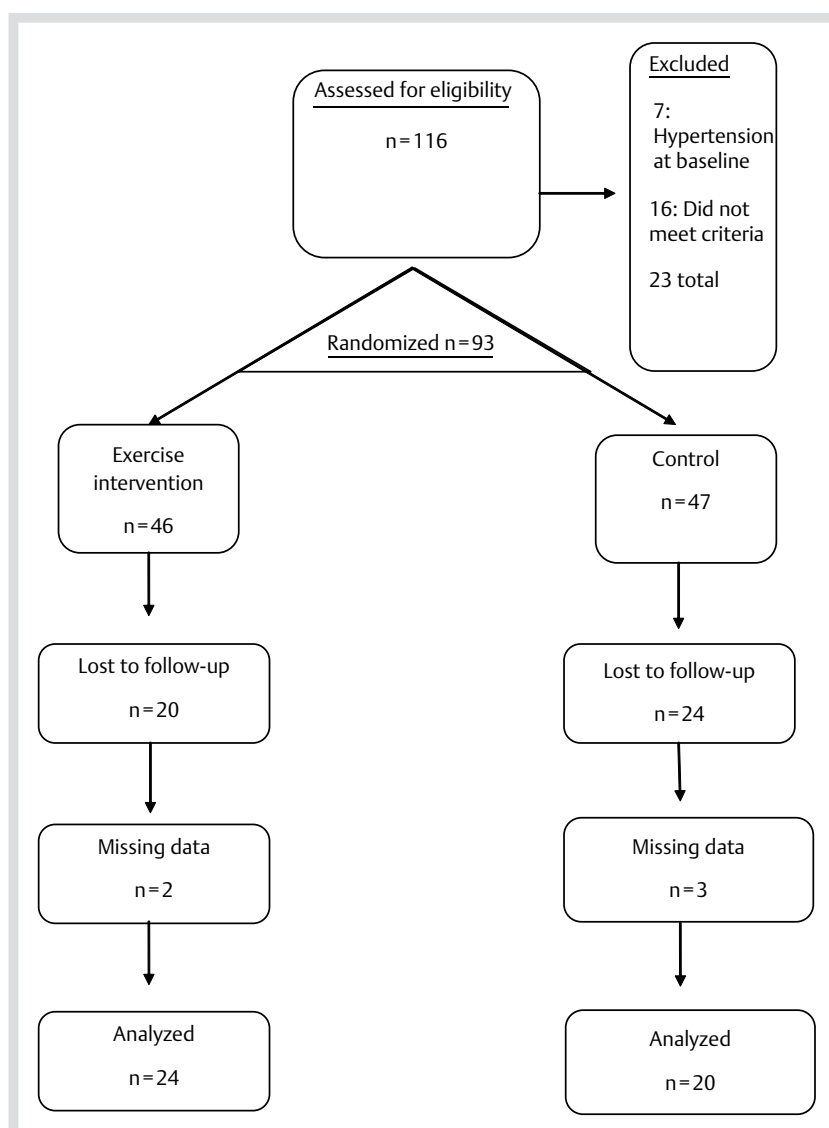

Fig. 1 Study recruitment flowchart. 
lection of demographic information, current medications, family health history, daily physical activity, and various psychometric instruments. Following the baseline data collection, participants were randomly assigned to one of 2 groups, intervention or control, using a random number table.

\section{Training protocol}

Participants who were randomized to the intervention group completed 30 min of aerobic exercise treadmill training at an intensity range of $50-70 \%$ of their age-predicted maximum heart rate (220-age in years) twice weekly for 6 weeks. Heart rate was monitored using Polar Heart Rate Monitors. Each treadmill session consisted of a 5-min warm-up period, followed by 30 min of training within the intensity range and then a 3-5-min cool-down. Treadmill speed and grade were adjusted during each session to keep the subjects within their prescribed intensity range.

Following the aerobic training session, participants completed upper and lower-body resistance training lasting approximately $20 \mathrm{~min}$. Exercises targeting the chest, upper back and triceps muscles were performed on plate-loaded Hammer Strength machines (Cincinnati, $\mathrm{OH}$ ), the upper anterior and posterior legs on Life Circuit machines (Life Fitness, Irvine, CA) and the biceps brachii and deltoids using free weights. Participants were given approximately $1 \mathrm{~min}$ of recovery time between exercises. Resistance was adjusted so that each participant could complete one set of 12 repetitions for each exercise while maintaining proper form. As strength increased, resistance was changed to keep the subjects at their prescribed training intensity. Sessions were separated by at least $48 \mathrm{~h}$ of recovery and lasted $1 \mathrm{~h}$ in total duration.

\section{Control group}

Control group subjects came to the CERC for the same amount of time and weekly frequency as the intervention participants. The participants were allowed to read a book, talk, watch television, or engage in other sedentary behaviors. This was done in an attempt to have an ideal controlled setting. All participants received cash compensation for their time regardless of group assignment. Participants were not scheduled to come in all at the same time, and there was some variation throughout the day as to when they were available. Therefore there was little social interaction while in the controlled setting unless they arrived with a friend who was also part of the study.

\section{Instruments}

Profile of mood states: Mood disturbance was measured using the brief Profile of Mood States (POMS-30) in which a series of mood states are rated according the participant's mood during a particular time frame. Instructions asked the participants to indicate "how you have been feeling during the past week including today." Individual sub-scales identify mood factors: Tension/Anxiety, Depression/Dejection, Anger/Hostility, Vigor/Activity, Fatigue, and Confusion. Total mood disturbance is determined by adding together the sum of all sub-scales except Vigor/Activity, which is subtracted. Higher scores indicate an enhanced negative mood state. Internal reliability was supported in this sample with a Cronbach's alpha of 0.74 [19].

HIV symptom distress scale: The HIV Symptom Distress Scale (SDS) is a list of 31 symptoms experienced in HIV disease in which participants indicated the frequency of experienced symptoms within the past month and rated how much each symptom that was experienced bothered them on a 5-point scale ranging from 0 (not at all bothersome) to 4 (extremely bothersome). Reliability was supported in this sample with a Cronbach's alpha of 0.85 [27].

Perceived stress scale: Measuring perceived stress was conducted using the Perceived Stress Scale (PSS), a 10-item instrument with a potential score range of $0-40$, with a higher score indicating a greater perception of stress. The PSS has been shown as a valid tool for measuring the degree to which an individual finds life events of the last 30 days uncontrollable, unpredictable or overloaded. Internal consistency was demonstrated by a Cronbach's alpha of 0.78 [6].

Salivary cortisol: In a sub-sample of participants $(n=20)$ saliva samples were collected at 3 specific time points prior to randomization and again after completion of the assigned intervention. The time points in which each participant were all instructed to collect a sample were immediately following awakening $(W), 1 \mathrm{~h}$ later $(\mathrm{W}+1)$, and $2 \mathrm{~h}$ post-awakening $(\mathrm{W}+2)$. Once the sample was returned to the CERC that same morning the Salivette ${ }^{\circledR}$ tubes were centrifuged at $39000 \mathrm{~kg}$ for $5 \mathrm{~min}$ in order to extract as much of the saliva that was accumulated as possible. The total amount of saliva that accumulated at the bottom of the Salivette ${ }^{\circledR}$ was collected and immediately measured by volume and placed in a $-80^{\circ} \mathrm{C}$ freezer until ready for analysis. Following study completion, salivary cortisol was analyzed in duplicate, using a colorimetric sandwich ELISA (R\&D Systems, Minneapolis, MN) with an intra-assay coefficient of variance of $5.6 \%$. The area under the curve (AUC) was calculated by applying Simpson's $1 / 3$ rule, using the 3 time points in which saliva was collected (awakening, $+1 \mathrm{~h},+2 \mathrm{~h}$ ).

\section{Statistical analysis}

Due to a lack of normality within the POMS sub-scales and PSS datasets a square root (sqr) transformation was completed on those variables prior to data analysis. To assess differences within and between groups means following the intervention, repeated measures analysis of variance (ANOVA) were used with all questionnaire and salivary cortisol data. There were no significant differences between the groups at the start of the intervention.

\section{Results}

$\nabla$

The demographic characteristics of the participants of this study are detailed in $\bullet$ Table 1 . The total sample of 49 consisted of 37 men and 12 women consisting of 31 African-Americans, 16 Caucasians, 1 Asian, and 1 other. All participants in this study had documented HIV serostatus, with 31 HIV + asymptomatic (63\%), $5 \mathrm{HIV}+$ symptomatic (10\%) and 1 missing data point. The remaining 12 participants reported a current disease status of AIDS (25\%). 36 participants were receiving combination antiretroviral therapy (88\%).

- Table 2 presents descriptive statistics of PSS, POMS total scores and individual sub-scale scores separated by EX and CON groups, as well as self-reported frequency of HIV-related symptoms experienced and their associated distress prior to randomization. The POMS sub-scales of interest were depression and fatigue. Scores from the SDS were added together and separated 
into frequency of symptoms experienced and their associated distress.

Following a 6-week exercise intervention no changes were observed among self-reported HIV-related symptom frequency or the associated distress ( 0 Table 3 ). The mean scores of both treatment groups indicate an average frequency of more than 10 HIV-related symptoms experienced within the last month accompanied by similar levels of reported symptom distress. In addition, the burden of frequent symptoms experienced daily was shown to enhance the level of psychological distress as measured by symptom distress among this sample of HIVinfected persons.

- Table 3 also shows the changes in PSS, POMS total and 2 of the POMS subscales (fatigue and depression) following the 6-week intervention among both groups comparing pre-test with post-

Table 1 Demographic characteristics of HIV-infected males and females.

\begin{tabular}{|c|c|c|c|}
\hline & Variable & Exercise & Control \\
\hline & $\mathrm{N}$ & 26 & 23 \\
\hline & age & 42.7 & 42.0 \\
\hline \multirow[t]{2}{*}{ gender } & male & 19 & 18 \\
\hline & female & 7 & 5 \\
\hline \multirow[t]{3}{*}{ ethnicity } & African-American & 16 & 15 \\
\hline & Caucasian & 8 & 8 \\
\hline & other & 2 & \\
\hline \multirow[t]{4}{*}{ disease status } & asymptomatic & 17 & 14 \\
\hline & symptomatic & 2 & 3 \\
\hline & AIDS & 6 & 6 \\
\hline & no answer & 1 & \\
\hline \multirow{3}{*}{$\begin{array}{l}\text { currently taking } \\
\text { ART? }\end{array}$} & yes & 17 & 19 \\
\hline & no & 4 & 1 \\
\hline & no answer & 5 & 3 \\
\hline
\end{tabular}

test scores. Due to a lack of normality within the PSS data, a Kruskall-Wallace non-parametric test was used to compare changes observed with PSS scores and found no significant difference within the EX group following the 6-week intervention. However, the CON group showed a significant increase in reported PSS scores $(p=0.04)$, suggesting the exercise intervention prevented a similar increase in perceived stress for those in the EX group. Participants who completed the exercise intervention exhibited a significant decrease $(p=0.003)$ in self-reported mood disturbance, which dropped from $31.92 \pm 6.87$ pre-intervention to $6.38 \pm 4.51$ post-intervention. No change was observed among the participants randomized to the CON group. At the end of 6 weeks only the participants who completed the moderate intensity exercise intervention showed a significant reduction in self-reported depression $(p=0.03)$, but not fatigue $(\mathrm{p}=0.175)$.

- Fig. 2 shows the differences between pre- to post-intervention of salivary cortisol total AUC within both groups. As seen in this figure, cortisol measurements upon awakening were $5.5 \mathrm{ng} / \mathrm{ml}$ for the exercise group and $3.8 \mathrm{ng} / \mathrm{ml}$ for the control. At the end of 6 weeks only the participants who completed the moderate intensity exercise intervention showed a significant reduction in total AUC of salivary cortisol $(\mathrm{p}<0.001)$.

\section{Discussion}

The purpose of this investigation was to determine the effects of a 6-week moderate intensity exercise intervention on selfreported mood states, frequency of self-reported symptoms and psychological distress among PLWHA. Compared to sedentary controls those who completed 6 weeks of structured aerobic and

Table 2 Descriptive statistics for measurements pre-intervention.

\begin{tabular}{|c|c|c|c|c|c|c|}
\hline \multirow[b]{2}{*}{ Scale } & \multicolumn{3}{|c|}{ Exercise $(n=24)$} & \multicolumn{3}{|c|}{ Control $(n=20)$} \\
\hline & Mean & SE & Range & Mean & SE & Range \\
\hline symptom & 15.39 & 2.54 & $1-40$ & 18.65 & 3.22 & $2-48$ \\
\hline distress & 13.08 & 2.23 & $0-34$ & 14.04 & 2.88 & $0-55$ \\
\hline perceived stress & 14.42 & 1.54 & $0-32$ & 15.21 & 1.52 & $0-27$ \\
\hline profile of mood states total & 31.92 & 6.87 & $(-) 13-104$ & 18.74 & 6.58 & $(-) 24-99$ \\
\hline \multicolumn{7}{|l|}{ POMS sub-scales } \\
\hline fatigue & 7.96 & 1.21 & $0-18$ & 6.70 & 1.18 & $0-19$ \\
\hline depression & 14.38 & 2.48 & $0-43$ & 9.39 & 2.03 & $0-35$ \\
\hline cortisol (ng/ml) * (AUC) & 11322.18 & 1813.59 & $9053-16712$ & 7616.75 & 1890.23 & $3047-12164$ \\
\hline
\end{tabular}

Table 3 Changes in symptom frequency and psychological distress pre and post intervention.

\begin{tabular}{|lcccc} 
& \multicolumn{2}{c}{ Exercise $(\mathbf{n = 2 4 )}$} & \multicolumn{2}{c}{ Control (n=20) } \\
Scale & Mean \pm SE (pre) & Mean \pm SE (post) & Mean \pm SE (pre) & Mean \pm SE (post) \\
symptom & $15.39 \pm 2.54$ & $14.385 \pm 2.41$ & $18.65 \pm 3.22$ & $18.74 \pm 3.92$ \\
\hline distress & $13.08 \pm 2.23$ & $10.58 \pm 2.08$ & $14.04 \pm 2.88$ & $12.30 \pm 3.03$ \\
perceived stress & $14.42 \pm 1.54$ & $17.61 \pm 0.88$ & $15.21 \pm 1.52$ & $19.55 \pm 1.34^{*}$ \\
\hline POMS total & $31.92 \pm 6.87$ & $6.38 \pm 4.51^{*}$ & $18.74 \pm 6.58$ & $16.70 \pm 5.14$ \\
POMS sub-scales & & & & \\
fatigue & $7.96 \pm 1.11$ & $5.71 \pm 1.22$ & $6.7 \pm 1.18$ & $7.1 \pm 1.58$ \\
depression & $14.38 \pm 2.48$ & $6.21 \pm 1.50^{*}$ & $9.39 \pm 2.03$ & $8.2 \pm 2.08$
\end{tabular}

${ }^{*}$ Indicates significance of $p<0.05$

POMS: Profile of Mood States 


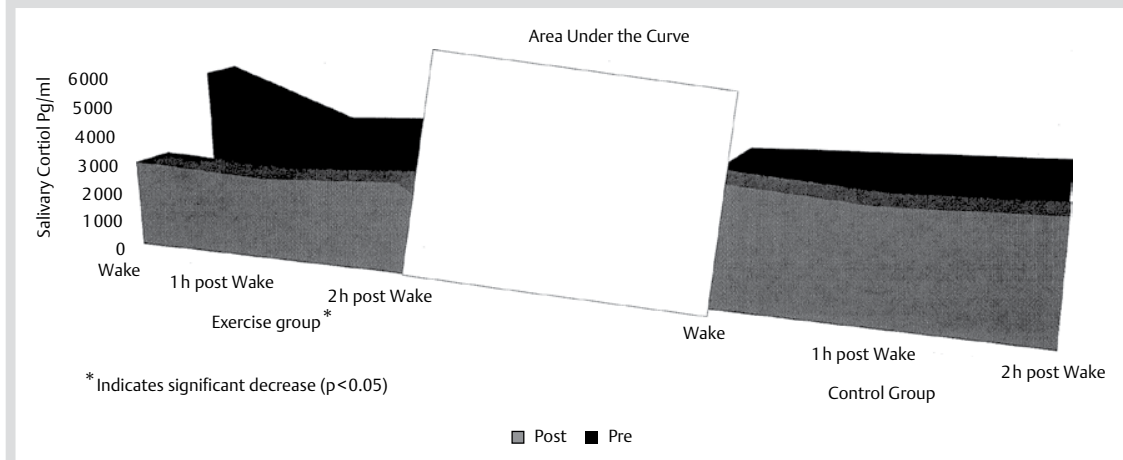

Fig. 2 Changes in AUC of salivary cortisol measured at 3 time points (awakening, $1 \mathrm{~h}$ postawakening, $2 \mathrm{~h}$ post-awakening).

Table 4 Current and previously published results.

\begin{tabular}{|c|c|}
\hline Author & Results \\
\hline $\begin{array}{l}\text { Hand et al. } \\
{[14,15]}\end{array}$ & $\begin{array}{l}\text { increased cardiorespiratory fitness (VO2peak Pre to } \\
\text { Post) } \\
31.6 \pm 2.1 \mathrm{ml} / \mathrm{kg} / \mathrm{min} \text { to } 39.9 \pm 1.9 \mathrm{ml} / \mathrm{kg} / \mathrm{min}^{*}\end{array}$ \\
\hline \multirow[t]{3}{*}{$\begin{array}{l}\text { Dudgeon et } \\
\text { al. }[10,11]\end{array}$} & $\begin{array}{l}\text { increased lean tissue mass (Pre to Post) } \\
56.3 \pm 1.1 \mathrm{~kg} \text { to } 57.1 \pm 1.1 \mathrm{~kg} *\end{array}$ \\
\hline & $\begin{array}{l}\text { decreased fat mass (Pre to Post for those }>\mathbf{2 0} \% \\
\text { body fat) } \\
28.6 \pm 1.5 \% \text { to } 27.7 \pm 1.6 \% \text { * }\end{array}$ \\
\hline & $\begin{array}{l}\text { increased strength } \\
1 \text { Rep Max increased for both lower body and upper } \\
\text { body* }\end{array}$ \\
\hline \multirow[t]{3}{*}{$\begin{array}{l}\text { current paper } \\
\text { Jaggers et al. }\end{array}$} & $\begin{array}{l}\text { decreased total mood state } \\
\text { see } \varnothing \text { Table } 3\end{array}$ \\
\hline & $\begin{array}{l}\text { decreased depression } \\
\text { see } \oslash \text { Table } 3\end{array}$ \\
\hline & $\begin{array}{l}\text { exercise group decreased total salivary cortisol AUC } \\
\text { at wake, } 1 \mathrm{~h} \text { post wake, and } 2 \mathrm{~h} \text { post wake } \\
11322.18 \pm 1813.59 \mathrm{ng} / \mathrm{ml} \text { to } 5547.87 \pm 1427.83 \mathrm{ng} / \mathrm{ml}^{*}\end{array}$ \\
\hline
\end{tabular}

resistance exercise twice a week significantly improved total mood state as measured by the POMS as well as the POMS subscale of depression. It should be noted that this was accomplished even without meeting the general physical activity guidelines recommending $\geq 150$ min of aerobic activity per week, and without any changes in disease status, perceived stress, symptomatology or symptom distress.

This investigation is the first to study the effects of a prescribed combination of aerobic and resistance exercise training on psychological disturbances in a clinical population. To our knowledge only 2 studies utilizing an exercise intervention to measure psychological effects among HIV patients have been reported. Both studies included aerobic exercise, but not resistance training, and found significant reductions in anxiety and depression $[22,29]$. Similar to our investigation, Neidig et al. measured total mood disturbance and depression using the POMS [29]. Although our findings confirm those of Neidig et al. our population showed a greater improvement in total POMS score which dropped to standard normative values, suggesting a clinically significant finding. In fact, 19 out of 24 participants in the EX group showed a reduction in total POMS and depression scores. This difference could possibly be attributed to the additional resistance training component incorporated into our intervention.

Studies have shown resistance training alone to elicit similar improvements in mood state and depression that are often observed following aerobic training $[1,7,37]$, suggesting that the combination of the 2 may result in additional improvements. However these investigations included populations not living with HIV or other known chronic conditions. Even though our findings would support this hypothesis, further investigation is warranted to identify mechanisms for this greater improvement in mood when combining resistance with aerobic exercise training in clinical and general populations.

There are a number of potential mechanisms that may be responsible for the reduced depression and improvement in mood state with exercise training, although there were not any changes in symptomatology or disease status. Aerobic and resistance exercise both have multiple physiological benefits (i.e., increased cardiorespiratory fitness and strength, improvements in body composition, enhanced functional ability, etc.) that in turn lead to improvements in psychological health such as improved self-esteem and overall quality of life. Our participants increased cardiorespiratory fitness, improved body composition, and increased muscular strength which was previously reported in recent publications $[10,15]$. Using the same dataset we demonstrated positive changes in fitness, muscular strength and body composition (i. e., reduced fat mass). It is possible that these physiological improvements mediated the changes in mood and depression by enhancing self-image and improving self-esteem. For a more detailed list of these previous studies and their findings please refer to $\odot$ Table 4 .

Considering aerobic and resistance training both have very different physiological adaptations it would seem plausible to expect added psychological benefits when the 2 are combined during routine exercise training. However a major limitation with previous investigations among clinical and healthy populations is that they incorporated only one type of exercise training, but not both. There have only been a few investigations that compared the differences between aerobic and resistance training on psychological health by randomly assigning participants to either an aerobic or resistance training program. However, none included a group that combined the two. These studies reported similar psychological improvements between groups $[1,9,38]$.

In a sub-sample of participants, results show that the individuals in the EX group significantly decreased morning salivary cortisol by $49 \%$ when compared to the control group (which showed no change). To our knowledge this is the first clinical exercise study to report AUC measures of waking cortisol in HIV+ persons before and after an exercise intervention. This reduction in salivary cortisol may have been mediated by the reduction of depressive symptoms. Studies indicate that hyperactivity of the hypothalamic-pituitary-adrenal (HPA) axis in depressed individuals during stressful periods results in elevated circulating 
cortisol $[1,32]$. Exercise effectively reduces circulating levels of cortisol and depressive symptoms in a wide range of populations [28]. In this sub-sample all but 1 of the participants who decreased salivary cortisol upon awakening also decreased their total POMS and depression scores.

Dudgeon et al. showed a reduction in salivary cortisol following 6 weeks of a combination exercise intervention as well. However that investigation only reported cortisol measurements obtained at one time point (immediately upon awakening) before and after the intervention [11], whereas the current study shows significant reductions of the total cortisol in the course of $2 \mathrm{~h}$ suggesting a possible long-term reduction throughout the morning hours compared to non-exercisers.

Results of this investigation demonstrate that PLWHA are able to obtain beneficial results among self-reported psychological disturbances, primarily total mood state and depression, through a combination of aerobic and resistance training in as little as 6 weeks. The intervention did not, however, elicit any changes in self-reported frequency of symptoms, symptom distress, or fatigue. Even though there were not any changes in symptomatology or its related distress, PLWHA were still able to improve their mood state and reduce depression. This would suggest that resistance and/or aerobic training can enhance psychological well-being independent of symptomatology. Although perceived stress showed no change among participants completing the exercise intervention, there was a significant increase in the control group suggesting that exercise may prevent increases in perceived stress for individuals living with HIV.

It is important to note that this study is not without limitations. Many studies involving exercise training in HIV populations face the major limitation of small sample sizes, and ours is no exception. This lack of adequate sample sizes is of great concern and makes interpreting the results difficult because of low statistical power. Difficulties facing this population include inadequate transportation, poverty, housing issues, and opportunistic infections making participant retention difficult. These factors, among other personal reasons, could explain why our study showed a high attrition rate. Other limitations include the lack of multiple measures for depression making it difficult to compare our results with other clinical trials utilizing different questionnaires such as the Beck Depression Inventory and the Center for Epidemiological Studies-Depression Scale. We chose to use the POMS because it has proven to be a useful tool in detecting mood fluctuations associated with exercise, normative data has been established for specific groups making it practical for clinical interpretation, and it was initially developed for use with clinical populations.

\section{Conclusion}

$\nabla$

Routine aerobic and resistance training completed at a moderate intensity may serve as a viable option to help PLWHA manage depressive symptoms, while also providing additional health benefits associated with routine physical activity. These modest amounts of increased activity can easily be achieved by the individual and completed at his or her convenience. However, any potential long-term benefits warrant further investigation. The physiological and psychological benefits that can be achieved by any clinical population, not just HIV patients, following longterm routine physical activity are currently unknown.
In conclusion, our population still improved overall mood and reduced self-reported depression scores despite not having any changes in symptomatology or related distress. These findings indicate that combination aerobic and resistance training completed at a moderate intensity at least twice a week provides additional psychological benefits independent of disease status and related symptoms. This intervention, which was secondary to a current ART regimen, should be considered by health care practitioners as a viable complement for improving the psychological well-being of PLWHA currently taking ART.

\section{Acknowledgements}

$\nabla$

Support: This research was supported by Grant \#1 P20 MD001770 Project \#3 from NCMHD, National Institutes of Health. Further support was provided by the South Carolina Research Institute and the American College of Sports Medicine.

Conflicts of interest: The authors have no conflict of interest to declare.

\section{Affiliations}

${ }^{1}$ Applied Health Sciences, Murray State University, Murray, United States Exercise Science, University of South Carolina, Columbia, United States ${ }^{3}$ Health and Human Performance, College of Charleston, Charleston, United States

${ }^{4}$ College of Nursing, University of South Carolina, Columbia, United States

${ }^{5}$ College of Nursing, University of Tennessee, Knoxville, United States

\section{References}

1 Barbour KA, Blumenthal JA. Exercise training and depression in older adults. Neurobiol Aging 2005; 26 (Suppl 1): 119-123

2 Bopp CM, Phillips KD, Fulk LJ, Dudgeon WD, Sowell R, Hand GA. Physical activity and immunity in HIV-infected individuals. AIDS Care 2004; 16: 387-393

3 Carrico AW, Antoni $\mathrm{MH}$. Effects of psychological interventions on neuroendocrine hormone regulation and immune status in HIV-positive persons: a review of randomized controlled trials. Psychosom Med 2008; 70: 575-584

4 Centers for Disease Control and Prevention. Diagnoses of HIV Infection in the United States and Dependent Areas, 2011. In: HIV Surveillance Report, 2001; 23: 5-39

5 Cohen M, Arad S, Lorber M, Pollack S. Psychological distress, life stressors, and social support in new immigrants with HIV. Behav Med 2007; 33: $45-54$

6 Cohen S, Kamarck T, Mermelstein R. A global measure of perceived stress. J Health Soc Behav 1983; 24: 385-396

7 Dimeo F, Bauer M, Varahram I, Proest G, Halter $U$. Benefits from aerobic exercise in patients with major depression: a pilot study. Br J Sports Med 2001; 35: 114-117

8 Dobbels F, Decorte A, Roskams A, Van Damme-Lombaerts R. Healthrelated quality of life, treatment adherence, symptom experience and depression in adolescent renal transplant patients. Pediatr Transplant 2010; 14: 216-223

9 Doyne EJ, Ossip-Klein DJ, Bowman ED, Osborn KM, McDougall-Wilson $I B$, Neimeyer RA. Running versus weight lifting in the treatment of depression. J Consult Clin Psychol 1987; 55: 748-754

10 Dudgeon WD, Jaggers JR, Phillips KD, Durstine JL, Burgess SE, Lyerly GW, Davis JM, Hand GA. Moderate-Intensity Exercise Improves Body Composition and Improves Physiological Markers of Stress in HIV-Infected Men. ISRN AIDS 2012; 11: 145-127

11 Dudgeon WD, Phillips KD, Durstine JL, Burgess SE, Lyerly GW, Davis $J M$, Hand GA. Individual exercise sessions alter circulating hormones and cytokines in HIV-infected men. Appl Physiol Nutr Metab 2010; 35: $560-568$

12 Graham JE, Christian LM, Kiecolt-Glaser JK. Stress, age, and immune function: toward a lifespan approach. J Behav Med 2006; 29: 389-400

13 Hand GA, Lyerly GW, Jaggers JR, Dudgeon WD. Impact of Aerobic and Resistance Exercise on the Health of HIV-Infected Persons. Am J Lifestyle Med 2009; 3: 489-499 
14 Hand GA, Phillips KD, Dudgeon WD. Perceived stress in HIV-infected individuals: physiological and psychological correlates. AIDS Care 2006; 18: 1011-1017

15 Hand GA, Phillips KD, Dudgeon WD, William LG, Durstine JL, Burgess $S E$. Moderate intensity exercise training reverses functional aerobic impairment in HIV-infected individuals. AIDS Care 2008; 20: 10661074

16 Harding R, Molloy T, Easterbrook P, Frame K, Higginson IJ. Is antiretroviral therapy associated with symptom prevalence and burden? Int J STD AIDS 2006; 17: 400-405

17 Harriss DJ, Atkinson G. Ethical standards in sport and exercise science research: 2014 update. Int J Sports Med 2013; 34: 1025-1028

18 Henderson M, Safa F, Easterbrook P, Hotopf M. Fatigue among HIVinfected patients in the era of highly active antiretroviral therapy. HIV Med 2005; 6: 347-352

19 Horowitz M, Adler $N$, Kegeles S. A scale for measuring the occurrence of positive states of mind: a preliminary report. Psychosom Med 1988; 50: 477-483

20 Laaksonen E, Martikainen P, Head J, Rahkonen O, Marmot MG, Lahelma $E$. Associations of multiple socio-economic circumstances with physical functioning among Finnish and British employees. Eur J Public Health 2009; 19: 38-45

21 LaPerriere A, Klimas N, Fletcher MA, Perry A, Ironson G, Perna F, Schneiderman $N$. Change in $\mathrm{CD} 4+$ cell enumeration following aerobic exercise training in HIV-1 disease: possible mechanisms and practical applications. Int J Sports Med 1997; 18 (Suppl 1): S56-S61

22 LaPerriere AR, Antoni $M H$, Schneiderman N, Ironson G, Klimas N, Caralis $P$, Fletcher $M A$. Exercise intervention attenuates emotional distress and natural killer cell decrements following notification of positive serologic status for HIV-1. Biofeedback Self Regul 1990; 15: 229-242

23 Lee KA, Gay C, Portillo CJ, Coggins T, Davis H, Pullinger CR, Aouizerat $B E$. Symptom experience in HIV-infected adults: a function of demographic and clinical characteristics. J Pain Symptom Manage 2009; 38: 882-893

24 MacArthur RD, Levine SD, Birk TJ. Supervised exercise training improves cardiopulmonary fitness in HIV-infected persons. Med Sci Sports Exerc 1993; 25: 684-688

25 Miaskowski C, Aouizerat BE. Is there a biological basis for the clustering of symptoms? Semin Oncol Nurs 2007; 23: 99-105

26 Miller G, Chen E, Cole SW. Health psychology: developing biologically plausible models linking the social world and physical health. Annu Rev Psychol 2009; 60: 501-524

27 Murdaugh C, Walter S. Development of a scale to measure symptom frequency and distress in persons with HIV/AIDS. 1995; Unpublished Manuscript

28 Nabkasorn C, Miyai N, Sootmongkol A, Junprasert S, Yamamoto H, Arita $M$, Miyashita K. Effects of physical exercise on depression, neuroendocrine stress hormones and physiological fitness in adolescent females with depressive symptoms. Eur J Public Health 2006; 16: 179-184

29 Neidig JL, Smith BA, Brashers DE. Aerobic exercise training for depressive symptom management in adults living with HIV infection. J Assoc Nurses AIDS Care 2003; 14: 30-40
30 Nicholas PK, Voss J, Wantland D, Lindgren T, Huang E, Holzemer WL, Cuca Y, Moezzi S, Portillo C, Willard S, Arudo J, Kirksey K, Corless IB, Rosa ME, Robinson L, Hamilton MJ, Sefcik E, Human S, Rivero-Mendez $M$, Maryland M, Nokes KM, Eller L, Kemppainen J, Dawson-Rose C, Brion $J M$, Bunch EH, Shannon M, Nicholas TP, Viamonte-Ros A, Bain CA. Prevalence, self-care behaviors, and self-care activities for peripheral neuropathy symptoms of HIV/AIDS. Nurs Health Sci 2010; 12: 119-126

31 O'Connell-Edwards C, Jones DJ, Forehand R, Larkin K. CD4 count and physical symptoms among urban African American mothers with HIV: an examination of the role of optimism and depressive symptoms. J Clin Psychol Med Settings 2008; 15: 322-330

32 Pariante CM, Lightman SL. The HPA axis in major depression: classical theories and new developments. Trends Neurosci 2008; 31: 464-468

33 Paton NI, Elia M, Jebb SA, Jennings G, Macallan DC, Griffin GE. Total energy expenditure and physical activity measured with the bicarbonate-urea method in patients with human immunodeficiency virus infection. Clin Sci (Lond) 1996; 91: 241-245

34 Phillips AC, Burns VE, Lord JM. Stress and exercise: Getting the balance right for aging immunity. Exerc Sport Sci Rev 2007; 35: 35-39

35 Phillips KD, Sowell RL, Rojas M, Tavakoli A, Fulk LJ, Hand GA. Physiological and psychological correlates of fatigue in HIV disease. Biol Res Nurs 2004; 6: 59-74

36 Portillo CJ, Holzemer WL, Chou FY. HIV symptoms. Annu Rev Nurs Res 2007; 25: 259-291

37 Singh NA, Stavrinos TM, Scarbek Y, Galambos G, Liber C, Fiatarone Singh MA. A randomized controlled trial of high versus low intensity weight training versus general practitioner care for clinical depression in older adults. J Gerontol A Biol Sci Med Sci 2005; 60: 768-776

38 Stein PN, Motta RW. Effects of aerobic and nonaerobic exercise on depression and self-concept. Percept Mot Skills 1992; 74: 79-89

39 Stewart KE, Cianfrini LR, Walker JF. Stress social support and housing are related to health status among HIV-positive persons in the deep south of the United States. AIDS Care 2005; 17: 350-358

40 Strand $B H$, Tverdal A. Can cardiovascular risk factors and lifestyle explain the educational inequalities in mortality from ischaemic heart disease and from other heart diseases? 26 year follow up of 50,000 Norwegian men and women. J Epidemiol Community Health 2004; 58: 705-709

41 Sullivan PS, Dworkin MS. Prevalence and correlates of fatigue among persons with HIV infection. J Pain Symptom Manage 2003; 25: 329333

42 Thoni GJ, Fedou C, Brun JF, Fabre J, Renard E, Reynes J, Varray A, Mercier $J$. Reduction of fat accumulation and lipid disorders by individualized light aerobic training in human immunodeficiency virus infected patients with lipodystrophy and/or dyslipidemia. Diabetes Metab 2002; 28: 397-404

43 van Oort FV, van Lenthe FJ, Mackenbach JP. Material, psychosocial, and behavioural factors in the explanation of educational inequalities in mortality in The Netherlands. J Epidemiol Community Health 2005; 59: $214-220$

44 Von $A D$, Kang $D H$. Correlates of mood disturbance in women with breast cancer: patterns over time. J Adv Nurs 2008; 61: 676-689 